\title{
Distribution of Phytophthora spp. in Field Soils Determined by Immunoassay
}

\author{
S. A. Miller, L. V. Madden, and A. F. Schmitthenner
}

Department of Plant Pathology, The Ohio State University, Ohio Agricultural Research and Development Center, Wooster 44691. Accepted for publication 10 October 1996.

\section{ABSTRACT}

Miller, S. A., Madden, L. V., and Schmitthenner, A. F. 1997. Distribution of Phytophthora spp. in field soils determined by immunoassay. Phytopathology 87:101-107.

Populations of Phytophthora spp. were determined by enzyme-linked immunosorbent assay (ELISA) in field soils used for pepper and soybean production in Ohio. Soybean fields were sampled extensively (64 fields, $n=6$ samples per field over 2 years) and intensively (4 fields, $n=64$ samples per field in 1 year) to assess heterogeneity of $P$. sojae populations. Four pepper fields $(n=64)$, three of which had a history of Phytophthora blight (caused by $P$. capsici), also were sampled intensively during a 6-month period. Mean $(m)$, variance $(v)$, and measures of aggregation (e.g., variance-to-mean ratio $[\mathrm{v} / \mathrm{m}]$ ) of immunoassay values, translated to Phytophthora antigen units (PAU), were related to the disease history in each of the pepper and soybean fields. Mean PAU values for fields in which Phytophthora root rot (soybean) or blight (pepper) had been moderate to severe were higher than in fields in which disease incidence had been low or not observed. A detection threshold value of 11.3 PAU was calculated with values for 64 samples from one pepper field, all of which tested negative for Phytophthora by bioassay and

Diseases caused by Phytophthora spp. are common where poor drainage combined with irrigation or intensive rainstorms result in standing water in production fields for several hours to several days. $P$. sojae has been recognized as a serious threat to soybean production for nearly 40 years, with crop losses estimated at $\$ 50$ million yearly in Ohio alone (A. F. Schmitthenner, unpublished data). $P$. sojae is managed primarily by the deployment of genes in soybean cultivars that confer resistance to races of $P$. sojae, although not all widely grown cultivars contain an adequate complement of these genes (30). A related disease of increasing importance is Phytophthora blight of pepper and cucurbits, caused by $P$. capsici. Management options for these crops are limited, because resistant cultivars currently are not widely available and registered fungicides are only partially effective. Avoidance of $P$. capsici-infested fields is a viable management option in areas where suitable agricultural land is readily available. Prior knowledge of Phytophthora spp. presence, population density, and distribution in fields would permit growers to better utilize available land and, in the case of soybean, make decisions regarding use of diseaseresistant cultivars. However, obtaining such information has been hampered by the lack of rapid, efficient systems for detection of these pathogens in soil.

Detection and quantitation of Phytophthora species in soil is complicated by several factors, including the occurrence of different structures (oospores, chlamydospores, sporangia, and zoospores)

Corresponding author: S. A. Miller; E-mail address: miller.769@osu.edu

Publication no. P-1996-1206-01R

(C) 1997 The American Phytopathological Society
ELISA. Seven of the eight intensively sampled fields contained at least some detectable Phytophthora propagules, with the percentage of positive samples ranging from 1.6 to 73.4. Mean PAU values ranged from 1 to 84 (extensive soybean field sampling), 6 to 24 (intensive soybean field sampling), and 4 to 30 (intensive pepper field sampling); however, variances ranged from 0 to 7,774 (extensive sampling), 30 to 848 (intensive soybean field sampling), and 5 to 2,401 (intensive pepper field sampling). Heterogeneity of PAU was high in most individual soybean and pepper fields, with values of $v / m$ greater than 1 , and $\log (v)$ increasing with $\log (m)$, with a slope of about 2.0. Spatial autocorrelation coefficients were not significant, indicating there was no relationship of PAU values in neighboring sampling units (i.e., field locations) of the intensively sampled fields. Combined results for autocorrelations and $v / m$ values indicate that Phytophthora was highly aggregated in these fields but that the scale of the aggregation (e.g., average focus size) was less than the size of the sampling units. Because of the observed variability, we calculated that sample sizes of 20 or more would be needed to estimate precisely the mean density of Phytophthora in most cases.

Additional keywords: epidemiology, spatial patterns. and differences in the ability of these to germinate or be recovered in standard assays $(13,32)$. Oospores are the overwintering structures of $P$. sojae and can persist at least 4 years in soil (28). They also are presumed to be the principal overwintering structures of P. capsici in temperate climates $(4,5,23)$, and both the $\mathrm{A}^{1}$ and $\mathrm{A}^{2}$ mating types have been found in pepper fields sampled in Ohio (18) and elsewhere $(23,26)$. Thus, oospores are the primary structures of interest for preplant analysis of Phytophthora populations in soil. However, oospores of $P$. capsici germinate with very low frequency on selective media $(4,5,13,23)$; similarly, in vitro-produced oospores of $P$. sojae germinate asynchronously for a period of at least 30 days, even under ideal conditions (3). Although soil dilution plating methods have been effective for some species of Phytophthora, they generally are not suitable for very low levels of inoculum (20) and have not been useful in quantitation of $P$. sojae (A. F. Schmitthenner, unpublished data) or P. capsici (13). Seedling and leaf-disk bioassays have been developed for these pathogens but require labor-intensive techniques, such as dilution endpoint or most probable number methods, and, thus, are too time-consuming to be used routinely for detection of Phytophthora species in a large number of soil samples $(9,13,32)$.

Enzyme-linked immunosorbent assays (ELISAs) have been developed and are available commercially for detecting and quantifying a number of plant-pathogenic fungi, including species of Phytophthora, Septoria, Pythium, Rhizoctonia, Mycosphaerella, and Sclerotinia $(17,21)$. Many of these assays, including the Phytophthora ELISA, contain monoclonal antibodies that afford greater specificity than can be achieved with polyclonal antibodies. Multiwell ELISAs are being used routinely in Europe and Central America for detection and quantitation of $S$. no- 
dorum and $S$. tritici in wheat and $M$. fijiensis in banana, respectively (A. Binder, CIBA AG, personal communication). Timmer et al. (31) showed that ELISA values for citrus root tissue, determined with a Phytophthora assay similar to the one used in this study, were positively correlated with percent root infection and soil populations of $P$. parasitica in Florida orchards and with $P$. citrophthora propagule densities in California. Numerous studies have been published in which this immunoassay has been shown to be sensitive and specific for detection of Phytophthora spp. in various substrates, including plant tissue $(2,18,19,24)$ and water (1). Our preliminary studies on detection of $P$. sojae (29) and $P$. capsici (18) by ELISA demonstrated considerable promise for use of this method to detect populations of these pathogens in field soils.

The purposes of this study were to determine by immunoassays (i) the heterogeneity of populations of Phytophthora spp. in naturally infested fields and (ii) the sample size necessary to estimate precisely the mean population densities. We studied fields infested with $P$. sojae, a homothallic species that produces abundant oospores in soybean crops (28), and $P$. capsici, a heterothallic species for which the role of oospores in initiation of disease epidemics is less well characterized (5). Moreover, $P$. sojae generally behaves as a monocyclic pathogen, causing significant disease severity only if conditions are favorable during a brief period early in the crop cycle (28). P. capsici has both crown rot and aerial blight phases and is polycyclic whenever environmental conditions are conducive $(4,5,27)$. Soil water content $(12)$ and water drainage patterns (27) are considered significant factors in the spread of $P$. capsici in pepper fields. These factors may influence the distribution of propagules in the soil and, thus, the sampling procedures required for accurate detection.

\section{MATERIALS AND METHODS}

Soil sampling and assay. For extensive sampling of soybean field soils, six soil samples $(n=6)$ were collected during March and April from each of 42 and 22 fields in 1990 and 1991, respectively. Samples were taken near the edges of the test fields in two rows of three samples each, spaced $30 \mathrm{~m}$ apart. Each sample consisted of two 1.5-liter volumes of soil collected with a golf course cup cutter (LESCO, Sebring, FL). The soils were air-dried, passed through a burr mill, with burrs spaced $2 \mathrm{~mm}$ apart, mixed, and stored at room temperature until tested. Oospores and other Phytophthora structures, both free in soil and associated with organic matter, were recovered from $50-\mathrm{g}$ soil samples by flotation, and immunoassays were performed on this material as previously described (18). For soils sampled in 1990, two ELISA tests were conducted several months apart for each sample of each field. Immunoassays of the 1991 fields were performed at one

TABLE 1. Field descriptors for intensive sampling analysis of Phytophthora population densities in soybean and pepper fields in Ohio in 1992

\begin{tabular}{lcllcc}
\hline Sample & $\begin{array}{c}\text { Region } \\
\text { (Ohio) }\end{array}$ & \multicolumn{1}{c}{ Crop } & $\begin{array}{c}\text { Date } \\
\text { sampled }\end{array}$ & $\begin{array}{c}\text { Phytophthora } \\
\text { history }\end{array}$ & $\begin{array}{c}\text { Sample } \\
\text { grid }\end{array}$ \\
\hline A & NE & Soybean & 24 Jun. & + & $8 \times 8$ \\
B & NW & Soybean & 23 Jun. & ++ & $8 \times 8$ \\
C & NW & Soybean & 23 Jun. & +++ & $8 \times 8$ \\
D & NW & Wheat stubble ${ }^{\text {b }}$ & 15 Sep. & ++++ & $8 \times 8$ \\
I & S & Pepper & 10 Jul. & + & $4 \times 16$ \\
II & S & Pepper & 10 Jul. & - & $8 \times 8$ \\
III & NW & Pepper & 15 Sep. & ++++ & $8 \times 8$ \\
IV & NC & $\ldots$ c $^{\text {C }}$ & 16 Dec. & +++ & $4 \times 16$ \\
\hline
\end{tabular}

a Observations of Phytophthora disease in soybean or pepper crops at time of sampling or in 1 to 5 previous years: $-=$ no disease; $+=$ very low incidence; $++=$ low incidence $;+++=$ moderate incidence $;++++=$ high incidence .

b Severe Phytophthora root rot in soybeans in 1991.

c 1992 pepper crop residue (moderate Phytophthora blight) deep plowed into soil $\sim 2$ months before sampling. time on three subsamples from each soil sample to provide a mean ELISA value for each sample from each field.

For intensive sampling of pepper and soybean field soils, 64 soil samples $(n=64)$ were collected from each of eight fields in Ohio in 1992 (Table 1). Fields were selected to reflect a range of disease incidence (low or none to high) in both soybean and pepper and in different geographic locations. Soil in field III was sampled in the presence of diseased pepper plants, whereas the remaining fields were sampled early in the season (I, II, A, B, and C), after harvest and deep plowing of plant residue (including diseased plants) (IV), or in the presence of wheat stubble (D). No disease was observed in fields I, II, A, B, or C at the time of sampling. Sampling was done with $8 \times 8$ or $4 \times 16$ grid patterns (Table 1 ), with samples taken every $10 \mathrm{~m}$. This is a type of centric systematic area sample (10). Hierarchical sampling, in which the fields are divided into primary (e.g., 10-m-wide quadrats), secondary (e.g., 1-m-wide subquadrats), and smaller sampling units, was not performed, because there is no natural size of sampling units for soil assays. Furthermore, to detect the exact scale of aggregation (if aggregation is present at all) would necessitate multiple levels of sampling units and probably a very high number of observations, because the scale could be of the order of centimeters or less. Soil samples, each consisting of two 1.5-liter volumes of soil collected as described above, were prepared, and immunoassays were performed as previously described (18). There was no relation between the location of the soil samples and the placement of the crops.

The Phytophthora ELISA multiwell kit E (Neogen, Inc., East Lansing, MI) was used in all experiments. The kit is a doubleantibody ELISA containing polyclonal (capture) and monoclonal (conjugate) antibodies prepared to mycelial extracts of $P$. sojae. The assay reacts positively with all species of Phytophthora tested to date $(19,24)$, with approximately equivalent reactivity with $P$. sojae and $P$. capsici $(18,19)$. The lower limit of detection of the assay for $P$. sojae is 10 oospores per well or $25 \mathrm{ng}$ of mycelial protein per $\mathrm{ml}$ (19). It does not react positively with nonPythiaceous fungi but does react weakly with some species of Pythium when tested at high concentrations (19). Each sample was tested in two antibody-sensitized wells plus a nonsensitized (no bound antibody) control well. Absorbance values $(405 \mathrm{~nm}$ ) for nonsensitized wells were subtracted from mean absorbance values of the two test (sensitized) wells. In this way, any nonspecific background reactions caused by components of different types of soil were accounted for and eliminated from the calculations. Phytophthora antigen units (PAU) in each sample were calculated by a standard curve developed from dilutions of $P$. sojae mycelial extracts provided in the kit. One PAU is approximately equivalent to one $P$. sojae oospore (19). Absorbance values for standards of 0 to 200 PAU values usually ranged from 0 to $\sim 1.0$. Three subsamples were tested separately in each of the 64 samples, and the analyses were based on the 64 means per field for the intensive sampling study. The presence or absence of $P$. sojae or $P$. capsici in each of the intensively sampled soybean or pepper fields was confirmed by bioassay as described previously (18), utilizing soybean or pepper seedlings, respectively.

Data analysis. The mean $(m)$, variance $(v)$, variance-to-mean ratio $(v / m)$, and coefficient of variation of the mean $(C)$ for PAU values were calculated for each field. The relationship between $v$ and $m$ was quantified with Taylor's power law (7):

$$
\log (v)=\log (a)+b \log (m)
$$

in which $a$ and $b$ are parameters, estimated by linear regression (22). If one can assume that the calculated PAU is a count variable, then the slope of equation $1, b$, can be used to interpret the distribution or heterogeneity of Phytophthora in a field (7). When $b=1$ and $a=1(\log (a)=0)$, a random distribution is specified (i.e., $v=m$ [or $v / m=1]$ ), which is consistent with a Poisson statistical distribution for the data. When $b>1$, a clustered (ag- 
gregated) distribution is indicated (i.e., $v>m$ and $v$ is increasing faster than the mean). Even if PAU cannot be considered a count variable but is just a scaled absorbance value, the parameters of equation 1 indicate the magnitude of the heterogeneity in Phytophthora and how the variation changes with the mean. Equation 1 was fitted to the extensive sampling soybean data (fields with $n=6$ ) for 1990 and 1991 and for the pooled data. Additionally, equation 1 was fitted to the intensive sampling soybean and pepper data (fields with $n=64$ ). Standard errors of the estimated parameters were calculated, and the coefficient of determination $\left(R^{2}\right)$ was determined to assess goodness-of-fit.

For the intensively sampled soybean and pepper fields, the spatial autocorrelation $(r)$ of PAU values was calculated by the program by Reynolds and Madden (25). Spatial autocorrelations are measures of the degree of association of PAU values in proximal (neighboring) sampling units (i.e., field locations or quadrats). Large positive values of $r$ indicate that neighboring sampling units have similar values; large negative $r$ values indicate that neighboring sampling units have dissimilar values. First- and higher-order correlations were determined, although results are only shown for the first order. (First-order correlation measures associations between immediately adjacent sampling units; second-order correlation measures associations between sampling units one "location" farther away, and so on).

Because each soil sample from intensively sampled fields was tested in three subsamples, the heterogeneity of the proportion positive for the assayed Phytophthora spp. (i.e., above the detection threshold) in each location was determined by the methods for binary data described by Madden and Hughes (16). The index of dispersion $(D)$ was calculated as the observed variance of the proportion positive divided by the theoretical variance for a random distribution (i.e., binomial distribution). A value of $D$ equal to 1 indicates randomness.

The required sample size to achieve a desired value of $C(0.20)$ $\left(n_{0}\right)$ for PAU was determined based on the calculated $m$ and $v$ values (7). The general equation is written as

$$
n_{0}=v /\left(m^{2} C^{2}\right)
$$

If equation 1 holds, $v$ can be written as a function of $m$, and thus, $v$ can be eliminated from equation 2 to give

$$
n_{0}=a m^{\mathrm{b}-2} / C^{2}
$$

To test further the effects of sample size on the precision of estimated mean PAU values, a Monte Carlo-type simulation (7)

TABLE 2. Results of statistical analyses of quantitative enzyme-linked immunosorbent assay data for four soybean fields assayed for Phytophthora

\begin{tabular}{|c|c|c|c|c|}
\hline \multirow[b]{2}{*}{ Statistic } & \multicolumn{4}{|c|}{ Field } \\
\hline & A & B & $\mathrm{C}$ & $\mathrm{D}$ \\
\hline Mean $(m)$ & 5.78 & 5.72 & 20.17 & 24.42 \\
\hline Maximum & 28.0 & 20.0 & 178.3 & 137.3 \\
\hline Percent samples positive ${ }^{\mathrm{a}}$ & 19.4 & 5.6 & 45.3 & 73.4 \\
\hline Variance $(v)$ & 31.4 & 29.9 & 848.0 & 488.0 \\
\hline$v / m$ ratio & $5.43 * * \mathrm{~b}$ & $5.23 * *$ & $42.0 * *$ & $20.0 * *$ \\
\hline Coefficient of variation $(C)$ & 0.13 & 0.11 & 0.18 & 0.11 \\
\hline $95 \%$ confidence interval & $4.4-7.2$ & $4.5-7.0$ & $12.9-27.4$ & $18.9-29.9$ \\
\hline$n_{0}{ }^{\mathrm{c}}$ & 23.5 & 22.9 & 52.1 & 20.5 \\
\hline Index of $c$ & 1.0 & 1.2 & 1.2 & $1.3 * \mathrm{~d}$ \\
\hline Spatial autocorrelation $(r)^{\mathrm{e}}$ & -0.08 & -0.07 & 0.19 & 0.14 \\
\hline
\end{tabular}
population densities

${ }^{a}$ Percentage of 64 soil samples in each field for which Phytophthora antigen unit values are $>11.3$ (detection threshold)

${ }^{\mathrm{b}} v / m$ significantly greater than $1.0(P<0.01)$ based on a chi-square test $(7)$.

${ }^{c}$ Required sample size to achieve a coefficient of variation of the mean $(C)$ equal to 0.20 .

${ }^{\mathrm{d}} D$ (for aggregation of the proportion positive at each sampling location) significantly greater than 1 at $P<0.05$.

e First-order correlation (between immediately adjacent sampling units), none are significant. was performed with the data from the intensively sampled soybean and pepper fields. For each of the eight data sets, sample sizes of $n_{S}=6,12$, and 24 were simulated by randomly selecting from the 64 observations, using the Sample command of Minitab (Minitab, Inc., State College, PA). For each preselected $n_{S}, 100$ simulations were performed. For each simulation, mean PAU was determined. For each $n_{S}$ value, the percentage of the 100 simulated mean PAU values (e.g., when $n_{S}=6$ ) that fell within the $95 \%$ confidence interval of PAU, based on the complete $n=64$ values (Tables 2 and 3), was determined.

\section{RESULTS}

Extensive sampling. Mean PAU values $(m)$ for the 42 soybean fields sampled in 1990 ranged from 1 to 84 (Fig. 1), with $50 \%$ of the means between 6 and 29 and a median (of the means) of 16 . Thirty-three percent of the fields had means less than the threshold value of 11.3 (described below). For 1991, PAU means per field ranged from 2 to 68 , with $50 \%$ between 5 and 20 and a median of 12. Fifty percent of the field means were less than 11.3. The variance of PAU $(v)$ increased with the mean, and there was a linear relationship between $v$ and $m$ on a log scale (Fig. 1). Variances ranged from 0 to 7,774 in 1990 and from 1 to 3,349 in 1991. Almost all variance-to-mean ratios $(v / m)$ exceeded 1 , corresponding to the points above the $v=m$ line (Fig. 1). Coefficients of variation of the mean PAU values $(C)$ were high, with $87 \%$ greater than 0.20 and $46 \%$ greater than 0.40 (Fig. 1).

The power law (equation 1) provided a satisfactory fit to the $v: m$ data. Estimates of the slope $(b)$ for each year were close to or above 2.0 (Fig. 1), and $R^{2}$ values were 0.75 and 0.91 for 1990 and 1991, respectively. Equation 1 also provided a good fit to the pooled data from both years. Estimates of $\log (a)$ and $b$ for the pooled data were -0.09 (standard error $[\mathrm{SE}]=0.12$ ) and 1.97 $(\mathrm{SE}=0.10)$, respectively; $R^{2}=0.78$. The estimated $b$ was significantly different from $1.0(P<0.01)$ but not significantly different from 2 based on $t$ tests (7). The large value of $b$ indicated the high degree of heterogeneity of the PAU values in the fields.

Because the estimated $b$ was within $1.5 \%$ of $2, b=2$ was used in equation 3 to calculate the required sample size; in this case, $m$ is eliminated from the equation $\left(m^{2-2}=m^{0}=1\right)$. Using the estimate of $a\left(=10^{-0.09}=0.81\right)$ in equation 3 , a sample size $\left(n_{0}\right)$ of 20 would be needed to obtain a $C$ of 0.20 .

Intensive sampling: Soybean fields. Mean PAU values for the four intensively sampled soybean fields ranged from 5.7 to 24.4 ,

TABLE 3. Results of statistical analyses of quantitative enzyme-linked immunosorbent assay data for four pepper fields assayed for Phytophthora pop-

\begin{tabular}{|c|c|c|c|c|}
\hline \multirow[b]{2}{*}{ Statistic } & \multicolumn{4}{|c|}{ Field } \\
\hline & I & II & III & IV \\
\hline Mean $(m)$ & 5.83 & 4.32 & 20.04 & 29.66 \\
\hline Maximum & 12.0 & 10.7 & 169.7 & 200.0 \\
\hline Percent samples positive $^{a}$ & 1.6 & 0.0 & 28.1 & 46.9 \\
\hline Variance $(v)$ & 5.86 & 5.23 & $1,415.3$ & $2,401.0$ \\
\hline$v / m$ ratio & 1.00 & 1.21 & $70.6^{* * b}$ & $80.9 * *$ \\
\hline Coefficient of variation $(C)$ & 0.05 & 0.07 & 0.23 & 0.21 \\
\hline $95 \%$ confidence interval & $5.2-6.4$ & $3.8-4.9$ & $10.6-29.4$ & $17.4-41.9$ \\
\hline$n_{0}{ }^{\mathrm{c}}$ & 4.3 & 7.0 & 88.1 & 68.2 \\
\hline Index of dispersion $(D)$ & 1.0 & $\ldots$ & $1.9 * * \mathrm{~d}$ & $1.3^{*}$ \\
\hline Spatial autocorrelation $(r)^{\mathrm{e}}$ & 0.27 & 0.30 & -0.15 & -0.02 \\
\hline
\end{tabular}
ulation densities

a Percentage of 64 soil samples in each field for which Phytophthora antigen unit values are $>11.3$ (detection threshold).

${ }^{\mathrm{b}} \mathrm{v} / \mathrm{m}$ significantly greater than $1.0(P<0.01)$ based on a chi-square test $(7)$.

c Required sample size to achieve a coefficient of variation of the mean $(C)$ equal to 0.20 .

${ }^{\mathrm{d}} D$ (for aggregation of the proportion positive at each sampling location) significantly greater than 1 at $P<0.05(*)$ or $0.01(* *)$.

e First-order correlation (between immediately adjacent sampling units), none are significant. 
with maxima (per field) ranging from 20 to 178 . The percentage of samples in each field considered positive, with a threshold value calculated using data from pepper field II (described below), ranged from 5.6 to 73.4 (Table 2). The presence of $P$. sojae in each field was confirmed by bioassay (data not shown). Mean and maximum PAU values, as well as percent positive samples, were lower in fields with a history of low Phytophthora root rot incidence (fields $\mathrm{A}$ and $\mathrm{B}$ ) than in fields in which disease incidence was previously rated moderate to high (fields $\mathrm{C}$ and $\mathrm{D}$ ). Calculated values of $C$ were below 0.20 (Table 2), reflecting the larger sample size $(n=64)$ used for this study compared to the extensive sampling of 1990 and 1991: because $C$ decreases as $n$ increases (even when $v$ is constant), the intensively sampled fields had lower $C$.

There was a high degree of heterogeneity of PAU values within these four fields, as seen in the example distribution maps of two fields (Fig. 2). Visual observations were supported by the large $v$ 's and $v / m$ ratios (Table 2) and the generally increasing variances with the means. All $v / m$ values were significantly $(P<0.05)$ larger than 1 (Table 2), indicating the aggregated pattern of PAU values (7). Aggregation of the proportion of positive detections of Phytophthora across the 64 samples per field was fairly constant and less than for the mean PAU values per sampling unit: $D$ was close to 1 , and only one field had a $D$ value significantly greater than 1 (Table 2).

The power law (equation 1) provided a good fit to the data, although only four data points (four fields) were used in the regression analysis. The estimates of $\log (a)$ and $b$ were equal to
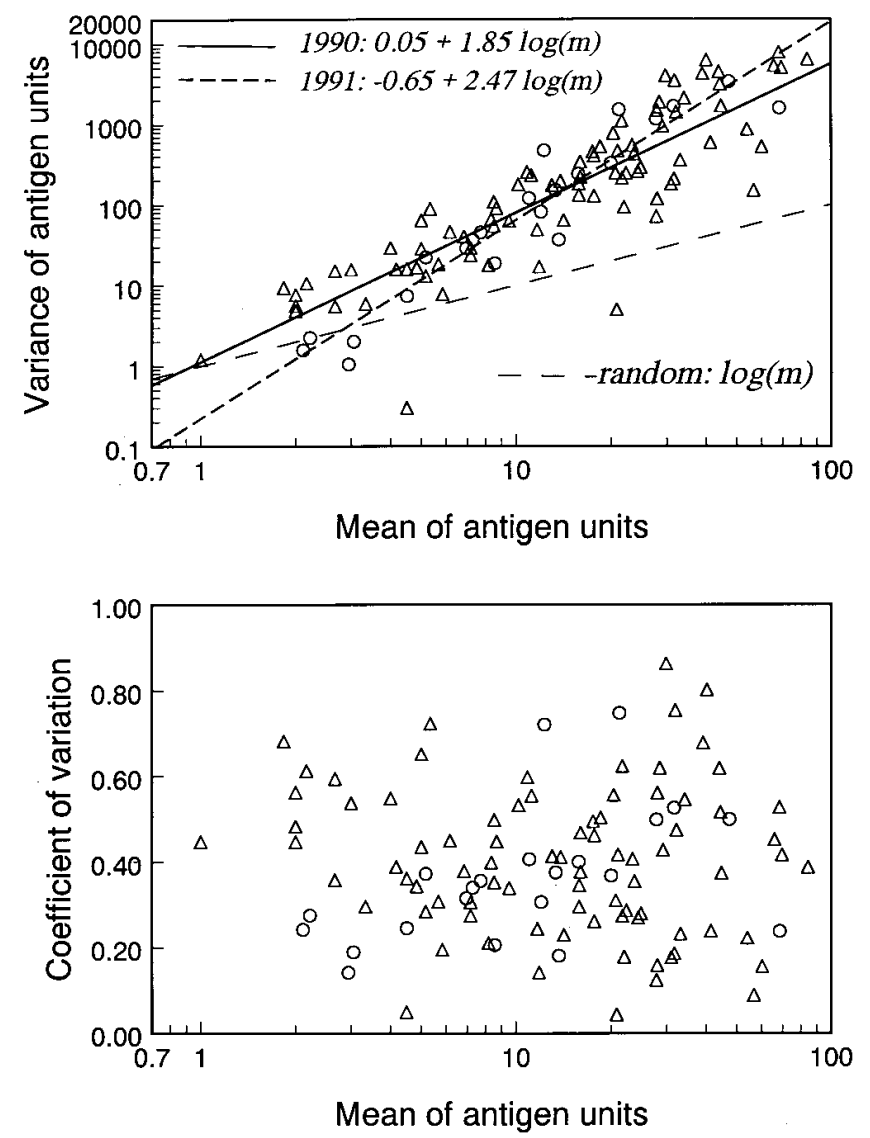

Fig. 1. A, Variance in relation to the mean for Phytophthora antigen units (PAU) determined by enzyme-linked immunosorbent assay for extensively sampled soybean field soils in 1990 (triangles) and 1991 (circles). B, Coefficient of variation in relation to the mean PAU for extensively sampled soybean field soils. Lines in A represent the fit of the power law model (equation 1) to the data for each year (solid and short dashes) as well as the theoretical line for a random distribution (long dashes; equation 1, with $a=b=1$ ). The line for pooled 1990 and 1991 data in $\mathbf{A}$ is not visible because it nearly overlaps the line for 1990
$-0.17(\mathrm{SE}=0.39)$ and $2.20(\mathrm{SE}=0.36)$, respectively; estimated $b$ was significantly greater than $1(P<0.01)$ and not significantly different from 2. The $R^{2}$ value was 0.95 .

The spatial autocorrelations of PAU between sampling units (locations) were low and not significantly different from $0(P>0.15)$ (Table 2), indicating there was no relation between PAU in neighboring sampling units. First-order correlations were all less than 0.20 in absolute value; higher-order correlations also were low and
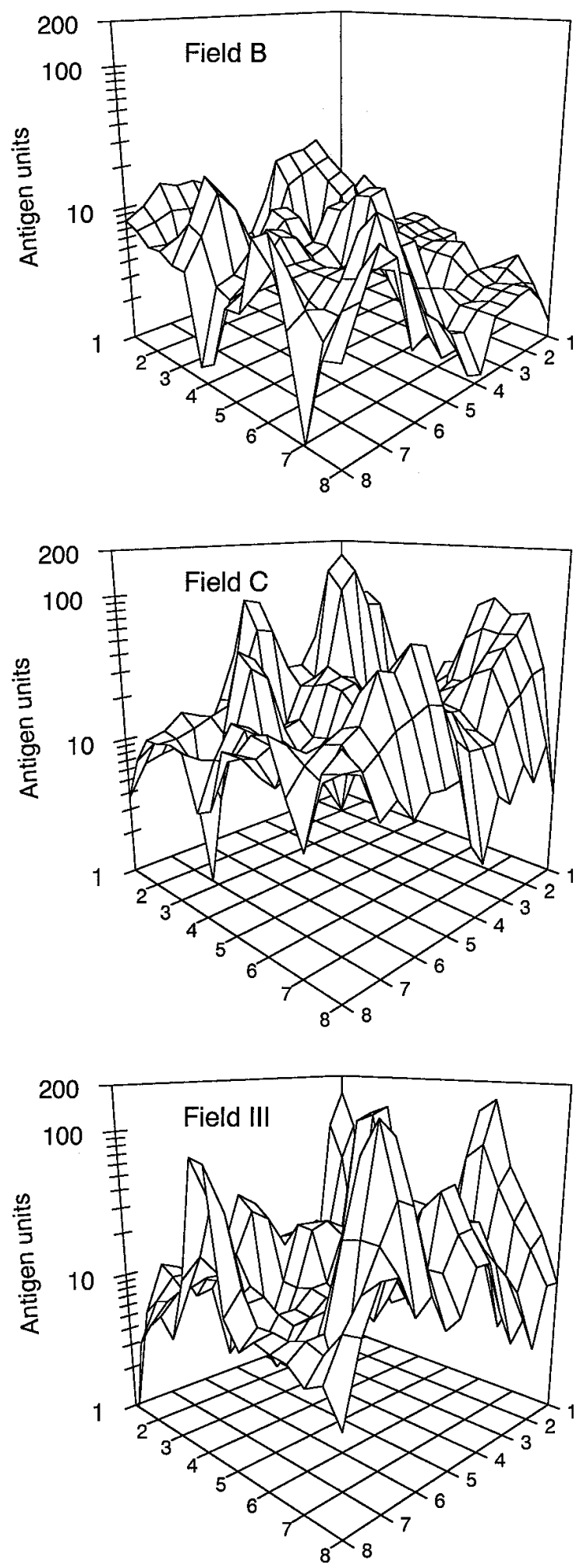

Fig. 2. Variation in Phytophthora antigen units within soybean (fields B and C) and pepper (field III) fields, determined by enzyme-linked immunosorbent assay. Samples were taken at 10 -m intervals in an $8 \times 8$ grid pattern. 
nonsignificant. Thus, the spatial scale of pathogen aggregation was less than the size of the sampling units (15).

Using equation 2 , the required $n_{0}$ to achieve a $C$ of 0.20 was calculated to be $\sim 20$ to 23 in three of the four fields (Table 2). Because $b>2$ with the power law, increasing $n_{0}$ with increasing $m$ was predicted. For the Monte Carlo sampling simulations, the mean PAU values obtained with $n_{S}=6$ simulations were only within the $95 \%$ confidence interval of the mean (e.g., 18.9 to 29.9 for field D) in 29 to $49 \%$ of the simulations (Table 4). However, with $n_{S}=$ 24 simulated samplings, mean PAU values were within the confidence interval at least $88 \%$ of the time for three of the four fields.

Intensive sampling: Pepper fields. For the four pepper fields sampled, mean PAU values ranged from 4.3 to 30 . The maxima per field ranged from 10.7 to 200 , and the percentage of positive samples ranged from 0.0 to 46.9 (Table 3). P. capsici was detected by bioassay in fields I, III, and IV but not in field II. The values of $C$ were between 0.05 and 0.23 . Even with a sample size of $n=64$, two of the fields had $C$ values greater than 0.20 , showing greater heterogeneity than the soybean fields (Table 2). PAU values for 63 of 64 individual samples tested from pepper field II, which had no history of Phytophthora blight, were below 10 PAU, the threshold suggested by the manufacturer. One sample resulted in a PAU value of 10.7. Using field II as a negative control, a detection threshold value of 11.3 PAU was calculated by adding the mean PAU of all 64 samples plus three times the standard deviation.

Unlike the intensively sampled soybean fields, variances only significantly $(P<0.01)$ exceeded the means in fields with large means (III and IV). The heterogeneity for field III is shown in Figure 2. In the other fields (I and II), variances were very similar to the means, an indication of a random distribution of PAU or the natural variation of ELISA results (field II). Similar results were found for the proportion of positive test results at each sample location. Calculated D was significantly greater than 1, indicating aggregation, in the two fields with large $v / m$ values, and not significantly different from 1 in the two fields with low $v / m$ values (Table 3 ).

The power law (equation 1) provided a good fit to the data, with estimates of $\log (a)$ and $b$ of $-1.70(\mathrm{SE}=0.45)$ and $3.55(\mathrm{SE}=$ 0.41 ), respectively. The $R^{2}$ value was 0.98 , and the estimated $b$ value was significantly different from both 1 and $2(P<0.01)$. The $b$ value reflects the large change in $v$ with increasing $m$, with $v$ close to $m$ at low mean and much larger than $m$ at high mean PAU (Table 3). As with the soybean data, first- and higher-order spatial autocorrelations were low and not significantly different from $0(P>0.05)$ (Table 3$)$. Results indicate there was no relation in PAU values between neighboring sampling units.

Predicted sample size for a $C$ value of 0.20 (equation 2) varied greatly with mean PAU, as expected with an estimate of $b$ greater than 2 (7). At low $m, n_{0}$ was less than 10 , but at high $m, n_{0}$ exceeded 65 (Table 3). The Monte Carlo sampling simulations had results similar to the soybean fields (Table 4). With $n_{S}=6$, mean PAU values were within the confidence interval (for the complete data set) in 29 to $50 \%$ of the simulations. With $n_{S}=24$, at least $86 \%$ of the simulations had means within the confidence interval. The consistent results for the simulated sampling of the four fields, even though calculated $C$ ranged from 0.05 to 0.23 (Table 3), was due to the width of the confidence interval for the mean based on all 64 observations: for the high-variation fields (III and IV), the confidence intervals were wide compared to the low-variation fields (I and II). Although use of a sampling with $n_{S}=24$ would be insufficient to achieve a $C$ equal to 0.20 for fields III and IV (Table $3, n_{0}$ ), it would be sufficient to obtain an estimated mean that was within the wide confidence interval for these fields.

\section{DISCUSSION}

The Phytophthora ELISA was a rapid and effective method for detection of Phytophthora species in soil. Mean PAU values ranged from 6 to 24 (intensive sampling in 1992) or from 1 to 84 (ex- tensive sampling in 1990 and 1991) for soybean fields and from 4 to 30 for pepper fields. These values corresponded to the Phytophthora disease history in the intensively sampled fields; fields with little or no known history of disease had significantly lower mean PAU values and percent samples positive than did those with a history of high incidence. It was expected that $P$. sojae and $P$. capsici would predominate in soybean and pepper fields, respectively, in this region because the principal rotational crops for both are nonhosts of Phytophthora. In this study, the presence of the appropriate species was confirmed by bioassay in ELISA-positive fields but not in the ELISA-negative field. Therefore, as shown in other studies, the lack of species specificity of this Phytophthora ELISA need not necessarily limit its use in situations where the cropping history of the field is known $(1,2,18,19,24)$.

Although the mean PAU values for pepper and soybean fields with very low to low (I, A, and B) and moderate to high (III, IV, $\mathrm{C}$, and D) disease incidence were similar, the percent samples positive were higher for soybean fields in each category compared to pepper fields. In soybean fields C and D, more than $45 \%$ of the samples tested were positive for Phytophthora, even though the fields were sampled in the absence of diseased plants. In fact, field D was sampled nearly 1 year after soybeans had been harvested and wheat planted. This is consistent with the behavior of homothallic $P$. sojae, which produces large numbers of oospores in plant tissue that may persist in soil for many years (28). On the other hand, only $1.6 \%$ of the soil samples tested in pepper field I were positive in ELISA early in the season in the absence of observable Phytophthora blight. This also is consistent with previous work showing that heterothallic $P$. capsici survives from year to year in field soil as very low numbers of oospores (5). This scenario is plausible for Ohio pepper field soils, from which we have consistently isolated both $\mathrm{A}^{1}$ and $\mathrm{A}^{2}$ mating types (18). For soil samples taken from pepper fields during production (field III) or within a few months after harvest and deep plowing (field IV), ELISA values may reflect detection of living or dead residual mycelia or sporangia associated with nondecomposed plant tissue, as well as oospores. Because it is not possible to distinguish between dead and living tissue with this ELISA, interpretation of PAU values also could be clouded by the presence of nonviable fungal tissue. On the other hand, ELISA may detect dormant oospores and, thus, provide a more realistic appraisal of Phytophthora population density than is possible with other methods.

No attempt was made in this study to establish inoculum threshold values for control treatments for Phytophthora disease in either soybean or peppers. This has been done for Phytophthora spp. on citrus, based on both rhizosphere soil dilution plate assays and Phytophthora ELISA (14,31). In California, fungicide treatment is recommended when propagule densities of Phytophthora spp. in rhizosphere soil are more than 15 to 20 propagules per g based on rhizosphere soil dilution plating assays. However, such results for a perennial crop and different Phytophthora species are unlikely

TABLE 4. Percentage of simulated samples from soybean and pepper fields, of three sample sizes $\left(n_{S}\right)$, in which the sample mean of Phytophthora antigen units (PAU) lies within the $95 \%$ confidence interval for the PAU values based on the complete 64 samples

\begin{tabular}{lccc}
\hline Field $^{\mathrm{a}}$ & $n_{S}=6$ & $n_{S}=12$ & $n_{S}=24$ \\
\hline A & $44 \%$ & $54 \%$ & $88 \%$ \\
B & $29 \%$ & $40 \%$ & $62 \%$ \\
C & $42 \%$ & $60 \%$ & $90 \%$ \\
D & $49 \%$ & $71 \%$ & $88 \%$ \\
I & $35 \%$ & $59 \%$ & $88 \%$ \\
II & $50 \%$ & $62 \%$ & $86 \%$ \\
III & $29 \%$ & $67 \%$ & $88 \%$ \\
IV & $38 \%$ & $67 \%$ & $87 \%$ \\
\hline
\end{tabular}

a Table 1 describes the eight fields, and Tables 2 and 3 contain the complete sampling results. 
to be directly relevant to soybean and pepper. Any treatment threshold for pepper or soybean would have to be based on soil sampling and analysis done before planting, because in both crops preventative at-plant applications of fungicide would be required to reduce or eliminate primary infections. In addition, Larkin et al. (13) found no relationship between results of a leaf-disk bioassay for $P$. capsici and disease severity in pepper fields in North Carolina. Additional work is needed to determine whether development of treatment inoculum thresholds for these diseases is a viable option.

Heterogeneity of Phytophthora in soil generally was large as measured by $v, v / m$, and $C$ of the PAU values. Moreover, heterogeneity of PAU values increased with the mean as indicated by the estimated $b$ values (generally $b \approx 2$ ) of equation 1 . The low variation at very low means (e.g., field II) mostly reflected the normal experimental variation of the ELISA. The calculated statistics demonstrate the aggregation (clustering) of PAU values, presumably representing Phytophthora propagules in the soil. The very high degree of heterogeneity for the two pepper fields with high means (Table 3, fields III and IV) could be the result of the polycyclic nature of Phytophthora blight (6): local multiplication of the pathogen, possibly associated with the crop, may result in increased differences in $P$. capsici population densities throughout a field. Our results are consistent with previous studies characterizing the aggregation of many soilborne plant pathogens $(8,15)$, generally based on the direct enumeration of propagule numbers rather than use of serological methods. Less variation was found for the proportion of positive tests at each sampling location compared to the PAU values in the intensively sampled fields. This is not surprising considering the variables being analyzed. For instance, consider an extreme case of only two sampling units $(n=2)$ with PAU means of 18 (subsamples of 9,18 , and 27) and 63 (subsamples of 9,36 , and 144). Here, $m=40.5$ and $v=1,011$ for the field, giving $v / m=25$. With a detection threshold of 11.3 , both sampling units have positive proportions equal to 0.667 ; thus, $m=0.667, v=0$, and $D=0$ for this example, even though PAU values were highly variable.

Despite the high degree of heterogeneity of Phytophthora found in many fields, there was no significant spatial autocorrelation in PAU values between adjacent (proximal) sampling units. Using spatial variograms (directly related to the spatial autocorrelation coefficients (Cliff and Ord [10]), Larkin et al. (12) also found no significant relationship in $P$. capsici inoculum between sampling units in pepper fields, even when diseased plants were highly correlated between sampling locations. Although Larkin et al. (12) interpreted this to mean that the pathogen was not aggregated, a more complete explanation is that the spatial scale of the aggregation could have been less than the size of the sampling units (15). As discussed by Cliff and Ord (10) and Madden (15), results of spatial associations (e.g., $r$ [Tables 2 and 3] or the semivariogram [12]) and distribution-related indices (e.g., $v / m$ ) can be combined to provide a more encompassing description of spatial patterns. Our combined results (high $v / m$ [at high $m$ ] and always low $r$ ) show that the pathogen was aggregated but that spatial scale (e.g., focus size of the pathogen propagules) was less than $10 \mathrm{~m}$, the distance between soil samples in the intensively sampled fields. Larkin et al. (12) did not test for this, but an analysis of the summary statistics presented in their Table 1 reveals that $\mathrm{v} / \mathrm{m}$ was significantly $(P<0.01)$ greater than 1 in the fields where inoculum density was determined (by dilution plating), and $D$ was significantly $(P<0.01)$ greater than 1 in the fields where percentage of infected leaf disks was determined (in a bioassay for inoculum density). Thus, the results of Larkin et al. (12) agree with ours: the pathogen was aggregated at a small spatial scale, less than the size of the sampling units.

The predicted sample size of 20 or more for soybean was determined utilizing all the data sets from 1990, 1991, and 1992 through the use of Taylor's power law (7) and $v / m$ ratios and confirmation with the Monte Carlo simulations. With pepper fields, fewer samples would be needed with very low pathogen density, e.g., when peppers are being planted in a field with no Phytophthora history (such as field II). Of course, the calculated sample size would simply be based on the natural background variation in the ELISA test. For pepper fields with high Phytophthora density, the heterogeneity was higher than in any soybean field, requiring much larger sample sizes to achieve $C=0.20$. Because of the lower variation in proportion data, it might appear that smaller sample sizes could be used with this measure of pathogen density. However, to estimate heterogeneity in proportions, one is required to have multiple test results (11) for each sample (three here), negating any benefits of a smaller number of samples. The estimation of sample numbers required to estimate mean Phytophthora population densities in field soils is independent of the method used to make the determination (i.e., ELISA), and therefore, large sample sizes would be needed for any other means adopted for detection of the pathogen.

\section{ACKNOWLEDGMENTS}

Salaries and research support provided by state and federal funds appropriated to The Ohio State University, Ohio Agricultural Research and Development Center. Immunoassay kits were provided by Neogen Corp., East Lansing, MI. OARDC Research Article 90-96. We thank A. Denning and $\mathrm{S}$. McClure for technical assistance.

\section{LITERATURE CITED}

1. Ali-Shtayeh, M. S., MacDonald, J. D., and Kabashima, J. 1991. A method for using commercial ELISA tests to detect zoospores of Phytophthora and Pythium species in irrigation water. Plant Dis. 75:305-311.

2. Benson, D. M. 1991. Detection of Phytophthora cinnamomi in azalea with commercial immunoassay kits. Plant Dis. 75:478-482.

3. Bhat, R. G., McBlain, B. A., and Schmitthenner, A. F. 1993. Development of pure lines of Phytophthora sojae races. Phytopathology 83:473477.

4. Bowers, J. H., and Mitchell, D. J. 1991. Relationship between inoculum level of Phytophthora capsici and mortality of pepper. Phytopathology 81:178-184.

5. Bowers, J. H., Papavisas, G. C., and Johnston, S. A. 1990. Effect of soil temperature and soil-water matric potential on the survival of Phytophthora capsici in natural soil. Plant Dis. 74:771-777.

6. Bowers, J. H., Sonoda, R. M., and Mitchell, D. J. 1990. Path coefficient analysis of the effect of rainfall variables on the epidemiology of Phytophthora blight of pepper caused by Phytophthora capsici. Phytopathology 80:1439-1446.

7. Campbell, C. L., and Madden, L. V. 1990. Introduction to Plant Disease Epidemiology. Wiley-Interscience, New York.

8. Campbell, C. L., and Noe, J. P. 1985. The spatial analysis of soilborne pathogens and root diseases. Annu. Rev. Phytopathol. 23:127-148.

9. Canaday, C. H., and Schmitthenner, A. F. 1982. Isolating Phytophthora megasperma f. sp. glycinea from soil with a baiting method that minimizes Pythium contamination. Soil Biol. Biochem. 14:67-68.

10. Cliff, A. D., and Ord, J. K. 1981. Spatial Processes: Models and Applications. Pion, Ltd., London.

11. Hughes, G., Madden, L. V., and Munkvold, G. P. 1996. Cluster sampling for disease incidence. Phytopathology 86:132-137.

12. Larkin, R. P., Gumpertz, M. L., and Ristaino, J. B. 1995. Geostatistical analysis of Phytophthora epidemic development in commercial bell pepper fields. Phytopathology 85:191-203.

13. Larkin, R. P., Ristaino, J. B., and Campbell, C. L. 1995. Detection and quantitation of Phytophthora capsici in soil. Phytopathology 85:10571063.

14. Lutz, A. L., and Menge, J. A. 1986. Citrus root health. II. Phytophthora root rot. Citrograph 72:33-39.

15. Madden, L. V. 1989. Dynamic nature of within-field disease and pathogen distributions. Pages 96-126 in: Spatial Components of Plant Disease Epidemics. M. J. Jeger, ed. Prentice Hall, Englewood Cliffs, NJ.

16. Madden, L. V., and Hughes, G. 1995. Plant disease incidence: Distributions, heterogeneity, and temporal analysis. Annu. Rev. Phytopathol. 33: 529-564.

17. Miller, S. A. 1996. Detecting propagules of plant pathogenic fungi. Pages 73-102 in: Advances in Botanical Research. Vol. 23, Pathogen Indexing Techniques. S. H. DeBoer, ed. Academic Press, London. 
18. Miller, S. A., Bhat, R. G., and Schmitthenner, A. F. 1994. Detection of Phytophthora capsici in pepper and cucurbit crops in Ohio with two commercial immunoassay kits. Plant Dis. 78:1042-1046.

19. Miller, S. A., Rittenburg, J. H., Petersen, F. P., and Grothaus, G. D. 1990. Development of modern diagnostic tests and benefits to the farmer. Pages 15-20 in: Monoclonal Antibodies in Agriculture. A. Schots, ed. Pudoc Scientific Publishers, Wageningen, Netherlands.

20. Mitchell, D. J., and Kannwischer-Mitchell, M. E. 1983. Relationship of inoculum density of Phytophthora species to disease incidence in various hosts. Pages 259-269 in: Phytophthora: Its Biology, Taxonomy, Ecology, and Pathology. D. C. Erwin, S. Bartnicki-Garcia, and P. H. Tsao, eds. The American Phytopathological Society, St. Paul, MN.

21. Mittermeier, L., Dercks, W., West, S. J. E., and Miller, S. A. 1990. Field results with a diagnostic system for the identification of Septoria nodorum and Septoria tritici. Brighton Crop Prot. Conf. Pests Dis. 2:757-762.

22. Neter, J., Wasserman, W., and Kutner, M. H. 1983. Applied Linear Regression Models. Richard D. Irwin, Homewood, IL.

23. Papavizas, G. C., Bowers, J. H., and Johnston, S. A. 1981. Selective isolation of Phytophthora capsici from soils. Phytopathology 71:129-133.

24. Pscheidt, J. W., Burket, J. Z., Fischer, S. L., and Hamm, P. B. 1992. Sensitivity and clinical use of Phytophthora-specific immunoassay kits. Plant Dis. 76:928-932.
25. Reynolds, K. M., and Madden, L. V. 1988. Analysis of epidemics using spatial autocorrelation. Phytopathology 78:240-246.

26. Ristaino, J. B. 1990. Intraspecific variation among isolates of Phytophthora capsici from pepper and cucurbit fields in North Carolina. Phytopathology 80:1253-1259.

27. Schlub, R. L. 1983. Epidemiology of Phytophthora capsici on bell pepper. J. Agric. Sci. 100:7-11.

28. Schmitthenner, A. F. 1985. Problems and progress in control of Phytophthora root rot of soybean. Plant Dis. 69:362-368.

29. Schmitthenner, A. F. 1990. Predicting yield loss from Phytophthora megasperma f. sp. glycinea in soybean with a quantitative immunoassay of Phytophthora in soil. (Abstr.) Phytopathology 80:962.

30. Schmitthenner, A. F., Hobe, M., and Bhat, R. 1994. Phytophthora sojae races in Ohio over a 10-year interval. Plant Dis. 78:269-276.

31. Timmer, L. W., Menge, J. A., Zitko, S. E., Pond, E., Miller, S. A., and Johnson, E. L. V. 1993. Comparison of ELISA techniques and standard isolation methods for Phytophthora detection in citrus orchards in Florida and California. Plant Dis. 77:791-796.

32. Tsao, P. H. 1983. Factors affecting isolation and quantitation of Phytophthora from soil. Pages 219-236 in: Phytophthora: Its Biology, Taxonomy, Ecology, and Pathology. D. C. Erwin, S. Bartnicki-Garcia, and P. H. Tsao, eds. The American Phytopathological Society, St. Paul, MN. 